\title{
Gift-giving, sharing and commodity exchange at Bookcrossing.com New insights from a qualitative analysis
}

\author{
Matteo Corciolani and Daniele Dalli \\ Department: Business Administration \\ University of Pisa \\ (forthcoming in Management Decision: http://www.emeraldinsight.com/products/journals/journals.htm?id=md) \\ This article is (c) Emerald Group Publishing and permission has been granted for this version to appear here \\ (https://arpi.unipi.it). Emerald does not grant permission for this article to be further copied/distributed or hosted \\ elsewhere without the express permission from Emerald Group Publishing Limited
}

\section{Structured Abstract:}

Purpose. Through an empirical analysis of a consumption community, this paper aims at demonstrating that the theories of gift-giving, sharing and commodity exchange should not be kept separated but integrated into a unifying model.

Design/methodology/approach. The paper provides new evidence about Bookcrossing.com, whose members share and give books as gifts; that is, physical goods rather than digital ones as in most of the communities considered in the literature. This community is analysed with qualitative tools, such as netnography, personal interviews and participant observation.

Findings. The main result of the analysis of Bookcrossing is that gift-giving is not the only process responsible for value creation and distribution in consumption communities: sharing and commodity exchange also play a role. Furthermore, the paper provides new evidence about aspects of gift-giving and sharing that have received limited attention in the literature: collective reciprocity and anonymous sharing.

Research limitations/implications. The limitations are related to the intrinsic properties of the methods employed (netnography, personal interviews and participant observation) and to the article, which analyses only one community and one product category. The implications refer to the role of gift-giving in consumption communities and its relationships with other processes: consumer gift systems are not only gifting platforms, but they and the elements of sharing and commodity exchange need to be integrated.

Practical implications. The empirical evidence and implications matter for a) the organisation and management of collaborative consumption platforms and b) the way in which traditional business models could and should interact with these platforms in an increasing number of businesses.

Social implications. This paper provides incremental evidence of the roles consumers play in the value creation process: they are not merely customers who pay for the value that companies have created; they actively participate in value creation through (collective) gift-giving, sharing and non-conventional forms of commodity exchange.

Originality/value. The paper adds new evidence of and original insights into gift-giving and collective forms of exchange. Moreover, it provides managerial implications of the analysed community for the book publishing industry.

Keywords: Collaborative consumption, consumer culture theory, qualitative methods, netnography, gift-giving, sharing, commodity exchange, consumption communities, Bookcrossing.

\section{Article Classification: Research Paper}




\section{Introduction}

Gift-giving can be regarded as a traditional form of exchange that enables consumption and one that technology has recently improved. Currently, many free resources are available both online and offline. They usually stem from individual acts of generosity and altruism that various forms of peerto-peer or social production platforms, such as Youtube, Myspace and Wikipedia, pool (Anderson, 2006, 2009; Benkler, 2006). A few specific consumer-to-consumer communities that consumer research has considered are: Couchsurfing (Cova and White, 2010), Freecycle (Arsel and Dobscha, 2011) and Geocaching (Scaraboto, 2010). In order to describe and explain how individual consumers participate in these processes by both giving and receiving gifts, a growing body of research has recently incorporated these diverse and new phenomena in the traditional gift-giving literature (Giesler, 2006; Hollenbeck et al., 2006; Weinberger and Wallendorf, 2012; Zeitlyn, 2003). Other constructs have also been renovated and improved to better explain important aspects of these relatively unexplored contexts: traditional commodity exchange and sharing (Belk, 2007, 2010; Marcoux, 2009).

This paper aims at empirically analysing a particular consumption community in order to better explain and expand the above-mentioned literature. Specifically, its main objective is to demonstrate that the theory of gift-giving and other concepts (i.e. sharing and commodity exchange) should be integrated into a unifying model in order to fully understand these innovative phenomena. In particular, this work - unlike previous research that tends to distinguish between and contrast various constructs (e.g. gift-giving, sharing, access-based consumption, etc.) - illustrates that these alternative ways of consuming goods and services are integrated and used contemporaneously in the same context. More precisely, the article is based on an empirical analysis of Bookcrossing.com, which is a community whose members read books and then 'release' them in public places, hoping they will be picked up by people who are expected to do the same. This context not only provides new insights into the gift-giving construct, but also helps researchers understand that other constructs, such as sharing and commodity exchange, likewise play important roles in these contexts and need to be taken into account. Furthermore, the paper provides new evidence of aspects of giftgiving and sharing that have received limited attention in the literature: anonymous sharing and collective reciprocity.

The empirical analysis was realised by means of qualitative tools (ethnography, netnography and interviews). Bookcrossing is a complex and under-explored (Dalli and Corciolani, 2008; MacLaran and Masterson, 2006) system of consumption with an important symbolic dimension. Qualitative methods were therefore deemed more appropriate to fully understand how the functional, symbolic, cultural and ideological dimensions of consumption interact.

The paper starts by briefly describing the Bookcrossing context and summarising the relevant literature on gift-giving and related constructs (i.e. commodity exchange, sharing). Thereafter, the 
methodology is described, followed by a presentation of the empirical research's main findings. In the last section, the theoretical and managerial implications are provided.

\section{How Bookcrossing works}

Bookcrossing is a community of book devotees who believe that no one should possess books and they should therefore be 'released' in public spaces and/or by means of other rituals. This community was created in 2001, when a dedicated website (www.bookcrossing.com) was launched on which book lovers could register their books and follow their 'journeys' once they had been released and swapped from one bookcrosser to another. In early 2012, one million bookcrossers had already joined the community and registered around 8.5 million books. After reading a book, they generally register it on the website, where it is assigned a unique specific code (BCID). The members then have to download the label with the BCID and any messages to the potential recipients. The book can then be 'released into the wild'; that is, in any public place where other people can find it (see Dalli and Corciolani, 2008). However, releasing books into the wild is not necessarily a success: according to the Bookcrossing website's estimates, very few of the released books are registered and again released. Consequently, new modes for releasing books have emerged that help the members improve their release performances. Additionally, personal motivations and the role members want to play in the community also affect the variety of bookgiving rituals.

These characteristics make Bookcrossing an ideal setting to better understand how alternative ways of consuming books coexist in the same context. To this end, the next section describes Bookcrossing characteristics in greater detail and links them directly to the theoretical debate on alternative ways of consuming. By building on previous theories and providing new information on Bookcrossing, which is not necessarily explained by existing theories, a new model is proposed that tries to integrate the three different and alternative ways of accessing consumption: commodity exchange, gift-giving and sharing.

\section{Bookcrossing and 'new' theories of consumption}

Bookcrossing.com started as a project to liberate books from the market logic domination. Believing that books should be gratis, bookcrossers release them in the environment as a gift for other people and society in general. Thus, the community is strongly rooted in the tradition of giftgiving and sharing, and takes an antagonist stance toward the market and traditional commodity exchange as a means of obtaining goods and services (Albinsson and Yasanthi Perera, 2012). Nevertheless, as will become evident, the internal relationships between the members still show aspects of traditional commodity exchange.

The literature has to date described how individuals participate in the market process in several (alternative) ways. In his discussion of the sharing construct, for example, Belk (2010) distinguishes 
three different and alternative consumption constructs: commodity exchange, gift-giving and sharing. However, as the empirical analysis of Bookcrossing will show, these prototypes can simultaneously play a role in the same context and consumers of the same community can use them to satisfy their specific needs and motivations. In this regard, the following sections provide a brief description of the important constructs of commodity exchange, gift-giving and sharing and how they can be better described and integrated from the Bookcrossing perspective.

\section{Commodity exchange}

According to Belk (2010), commodity exchange corresponds to the traditional customer/supplier (demand/supply) model, whose most elementary form is 'buying bread at a store for money' (p. 718). In practice, the entire marketing management literature has developed around the customer, who is expected to pay for the value that companies have created for him or her, as the central concept (e.g. Bagozzi, 1975). Owing to space limitations, this article does not discuss the commodity exchange construct in detail. In addition, it is very well grounded in the marketing and consumer behaviour literature. Nevertheless, it is an important basis of this analysis. Consumer research has also often considered it as the traditional way of consuming from which new models are differentiated. Web-based research, for example, has detailed how Internet development has resulted in consumers participating in the market process in different and non-traditional ways. As in the case of Bookcrossing, individuals may share resources through peer communities and avoid buying goods or services from the market (see also Giesler, 2006). Instead of buying and owning products, they may prefer to pay for temporary access to these products (e.g. Bardhi and Eckhardt, forthcoming). Interestingly, the analysis of Bookcrossing will show that important aspects of commodity exchange still play an important role in these new models of consumption.

\section{Gift-giving}

Gift-giving has a long tradition in social science studies as well as in the everyday life practice in many cultures. In consumer studies, it has received strong empirical support and has seen great theoretical development since the beginning of this discipline. More recently, interpretive researchers have revived the discipline (Arnould and Thompson, 2005). Within this tradition, various aspects of gift-giving have been addressed. Belk and Coon (1993), among others, have compared the economic and social exchange models of gift-giving. Importantly, both models indicate an exchange dimension in which the reciprocity of gift-giving is assessed and encouraged. Thus, according to the economic perspective, gift-giving is treated as a means of developing the interdependence between individuals (Sherry, 1983). Conversely, the social perspective deals with the cultural and symbolic aspects of social life rather than the pure economic ones; therefore, gift-giving is one of the rituals through which individuals create and support social order (Weiner, 1992). 
However, there are important aspects of Bookcrossing that somehow challenge previous theories. In its purest form, releasing books means leaving a book for other people, without expecting anything in return. Moreover, the practice of registering the books on the website does not serve as a means to enforce reciprocity, but as a performance measurement: those who register more (releasing and obtaining books) receive communal recognition and prestige. Therefore, although previous theories have often described gift-giving as a utilitarian activity (e.g. Belk and Coon, 1993; Sherry et al., 1993), the context of Bookcrossing seems to suggest that nonreciprocal forms of giftgiving do actually exist in practice.

Nevertheless, as Giesler (2006) also notes, the traditional dyadic perspective can be effectively employed to describe gift-giving between two individuals, which is the traditional setting for theory building in this area. Yet, more recent articles have addressed the communal dimension of consumption, focussing on all those activities in which goods and services are important due to their linking value (Cova, 1997; Cova et al., 2007). Consequently, new perspectives need to be developed to gain an understanding of how gift-giving works in a collective (not a dyadic) setting, since consumption communities often emerge in order to exchange given resources for free. Giesler (2006), for instance, develops a critique of the dyadic model and conceptualises the notion of a 'consumer gift system', which is described as a 'system of social solidarity based on a structured set of gift exchange and social relationships among consumers' (p. 283). Similarly, other scholars (Cheal, 1988; Raymond, 1999; Zeitlyn, 2003) examine open source systems, which are described as forms of communal gift-giving in which there is no formal obligation to give and reciprocate, but there are social and symbolic processes that provide incentives for giving: reputation, status, selfrealisation and so on.

Bookcrossing too can be considered a 'consumer gift system' (Giesler, 2006). That is, following Giesler's definition, bookcrossers self-identify with this unique gift system, which is perceived as something different and separate from the social environment ('social distinctions'). These bookcrossers structure particular forms of non-dyadic gifting relations ('norm of reciprocity') and share 'rituals and symbolisms', such as particular ways of exchanging books. However, whereas previous studies mostly described online consumer gift systems, Bookcrossing has an important offline dimension and its members share physical products. Therefore, they show themselves to be even more willing to sacrifice their personal resources in order to participate in the community.

\section{Sharing}

According to Belk (2007, p. 127), sharing is an alternative to private ownership, which, in turn, is central in gift-giving and commodity exchange. By sharing, two or more people enjoy the benefits (or share the costs) that flow from possessing a shared object. It is possible to share physical objects, such as a home, a car, a meal as well as more abstract ones, such as knowledge or relationships. In sum, sharing implies the voluntary lending, pooling and use of resources that are then collectively 
owned. Usually, this means that sharing is explicit and formally recognised: those who share are aware of one another and of their mutual commitment to the shared item. Car sharing is the most common and documented case in the literature (Bardhi and Eckhardt, forthcoming).

More specifically, Belk (2010, p. 725) suggests that sharing is related to the collective possession of resources, as in an extended family in which the members own and use such resources, which then become a sort of collective (quasi public) good. One of the traits of sharing communities is their detachment from the traditional market exchange system (Albinsson and Yasanthi Perera, 2012). That is, although consumers keep purchasing goods and services on the market, they tend to use them in a slightly different way: they often share their resources, they sometimes give them away as gifts, they barter, and, in some cases, they perform illegal activities (individual downloading is forbidden in some countries, while admitted in others).

Bookcrossing.com may also be regarded as a system of resource circulation (books): through individual acts (e.g. gifts, exchanges, etc.), books move from one person to another and, as such, they can be regarded as a type of collective resource. However, although Belk (2010) defines sharing as a personal activity, bookcrossers often share their books with unknown people. After releasing a book 'into the wild', for example, the donor does not know who will pick it up, nor does the recipient know who left it. Therefore, bookcrossers seem to practice a particular form of anonymous (impersonal) sharing (see also Weinberger and Wallendorf, 2012). Furthermore, it is not possible to look at Bookcrossing through only this lens, since - as the empirical evidence will show - sharing books is only one of many activities in which bookcrossers are involved, and not all of them are necessarily unselfish, altruistic or collaborative. Indeed, since Bookcrossing members possess different personal characteristics and motivational structures, the community has evolved to offer a diverse set of options for stimulating the gift-giving and sharing attitude.

\section{Summary and paper's aims}

As discussed above, the literature tends to regard commodity exchange, gift-giving and sharing as discrete alternatives that consumers may choose (Belk, 2010). In certain cases, the superiority (or inferiority) of one of the alternatives is proclaimed. For example, gift-giving is often considered an alternative to commodity exchange, while, unlike buying, peer-to-peer sharing is regarded as a crime. Belk (2010) explicitly compares sharing, gift-giving and commodity exchange, and defines them as three different paradigms. Similarly, Marcoux (2009) argues that individuals sometimes consider receiving gifts distasteful and prefer purchasing goods. Therefore, an implicit opposition has been established between the two alternatives.

Unlike previous articles that address similar empirical contexts, this work does not focus on giftgiving or any other of the discrete processes (i.e. commodity exchange and sharing). Conversely, it aims at presenting evidence from the Bookcrossing community in order to show the simultaneous presence of and interaction between different exchange forms. As also evidenced in Figure 1, it 
introduces a new model in which the classic constructs of commodity exchange, gift-giving and sharing are integrated. Within consumption communities, people with different motivations, aims and identities coexist and employ different, specific and - sometimes - context-dependent forms of exchange. For example, the hard-core members are generally more involved in the community activity, while lurkers simply want to have fun, meet new people and so on. Hence, depending on their different motivations and objectives, they may end up using commodity exchange, gift-giving or sharing as their preferred way of consuming books.

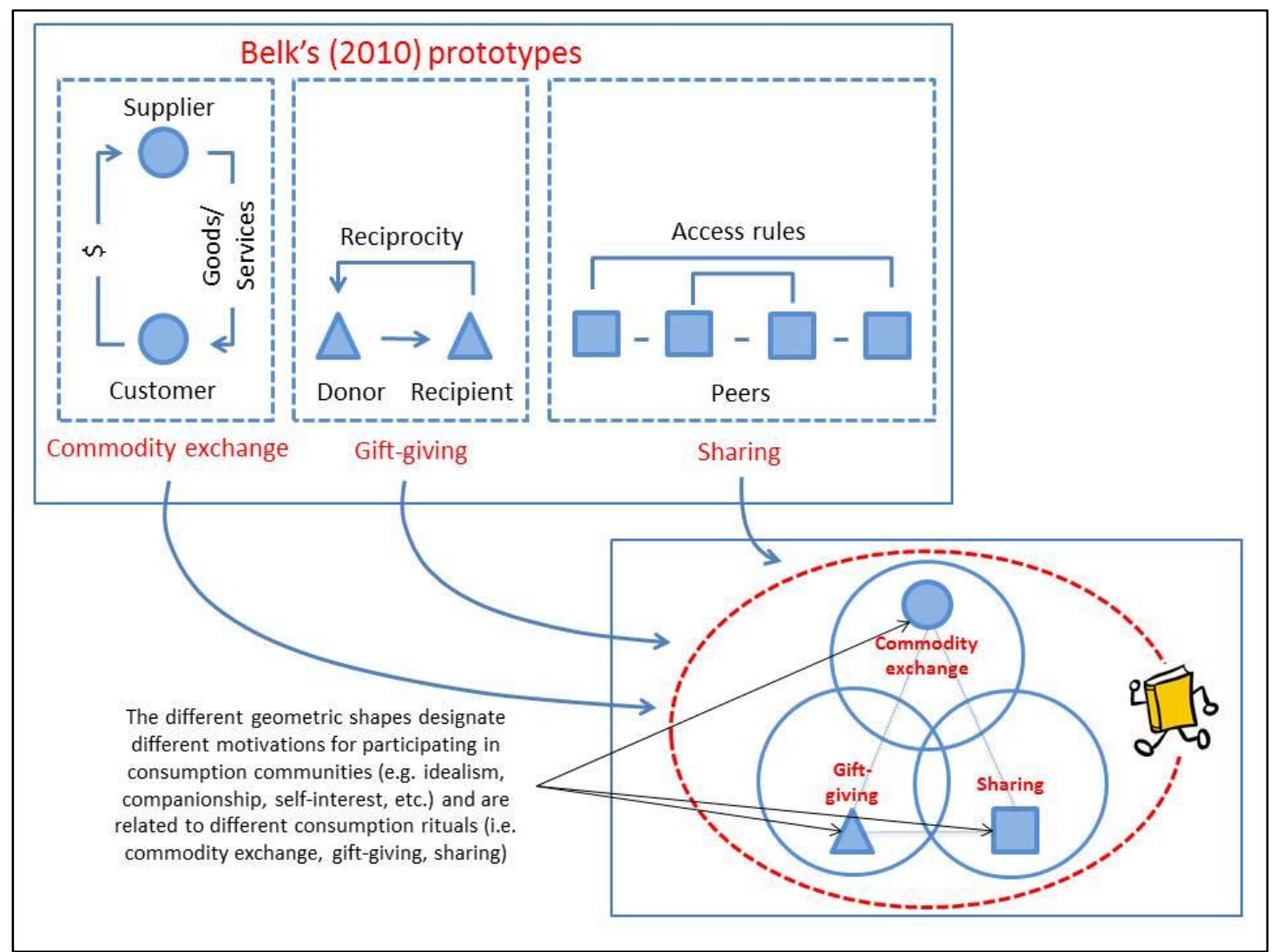

Figure 1. The coexistence of commodity exchange, gift-giving and sharing within consumption communities

The empirical analysis presented below helps explain that these three prototypes should be viewed as different but complementary and mutually integrated. Furthermore, the Bookcrossing evidence shows that some of the constructs discussed above need to be integrated and require further development as the specific traits of the context under investigation could be applied to similar cases and phenomena.

\section{Methodology}

Most of the empirical evidence in this field is grounded in qualitative methods; for instance, consumer gift systems have been analysed with virtual ethnographies (Hine, 2000), ethnographies (Arnould and Price, 2006; Arnould and Wallendorf, 1994), netnographies (Kozinets, 2002b, 2010) 
and interviews (Thompson, 1997), which are often linked to quantitative surveys. However, although there are certain excellent examples of quantitative studies on these phenomena (e.g. Becker and Clement, 2006), the majority of research papers on gift-giving communities employs qualitative methods (see Arnould and Thompson, 2005). Additionally, given the development of the Internet as a source of information and that the majority of the data available on the Internet consist of text and images, qualitative research methods form the fundamental basis for developing research in this context (see Kozinets, 2010).

Owing to its original combination of functional (e.g. receiving books for free) and symbolic (e.g. contributing to book 'liberation') properties, the Bookcrossing community is particularly suitable to provide further insights into gift-giving and other related constructs. As such, it was analysed using a combination of qualitative tools: netnography, ethnography and interviews. Since bookcrossers mainly interact on-line, netnography (Kozinets, 2002b, 2010) was employed to analyse their forum discussions. In addition, participant observation (Daymon and Holloway, 2002; Sayre, 2001) and indepth interviews (McCracken, 1988) were used to also investigate offline contexts, such as bookcrossers' local meetings.

\begin{tabular}{|c|c|c|}
\hline Sources & $\begin{array}{l}\text { Content } \\
\text { analysed }\end{array}$ & Motivation for analysing them \\
\hline \multicolumn{3}{|l|}{ Official Bookcrossing website } \\
\hline Somebodies and Nobodies forum & 45 threads & \multirow{3}{*}{$\begin{array}{l}\text { More involved members generally use them to } \\
\text { discuss organisational issues that are } \\
\text { particularly relevant for the entire community }\end{array}$} \\
\hline Wild Animus forum & 6 threads & \\
\hline $\begin{array}{l}\text { Activists, Enthusiasts, Hobbyists, } \\
\text { and Wannabees forum }\end{array}$ & 182 threads & \\
\hline Introduce Yourself forum & 301 threads & \multirow{2}{*}{$\begin{array}{l}\text { They provide an interesting perspective on how } \\
\text { new members introduce themselves to the } \\
\text { community and why they join it }\end{array}$} \\
\hline Newbies forum & 132 threads & \\
\hline Release Challenges forum & 114 threads & $\begin{array}{l}\text { It is mainly frequented by members interested in } \\
\text { playful activities related to Bookcrossing }\end{array}$ \\
\hline Site Watch forum & 62 threads & \multirow{2}{*}{$\begin{array}{l}\text { They help provide an understanding of how } \\
\text { bookcrossers relate to the rest of the world }\end{array}$} \\
\hline $\begin{array}{l}\text { Bookcrossing Site Announcements } \\
\text { forum }\end{array}$ & 93 threads & \\
\hline Feature Requests forum & 114 threads & $\begin{array}{l}\text { It deals with members' requests and ideas, } \\
\text { enabling a better understanding of what they } \\
\text { really want from the community }\end{array}$ \\
\hline $\begin{array}{l}\text { Bookrings, Bookrays and } \\
\text { Bookboxes forum }\end{array}$ & 74 threads & $\begin{array}{l}\text { It allows an understanding of how these } \\
\text { particular Bookcrossing rituals work }\end{array}$ \\
\hline Testimonials & 61 posts & $\begin{array}{l}\text { They clearly express the members' motivations } \\
\text { for participating in the community and their aims }\end{array}$ \\
\hline \multicolumn{3}{|l|}{ Other sources } \\
\hline Italian Bookcrossing website & 70 posts & \multirow{3}{*}{$\begin{array}{l}\text { Since the authors were also familiar with these } \\
\text { two languages, they decided to use these further } \\
\text { sources to compare global and local data }\end{array}$} \\
\hline Italian Bookcrossing mailing list & $\begin{array}{c}732 \\
\text { messages }\end{array}$ & \\
\hline Spanish Bookcrossing website & 104 posts & \\
\hline
\end{tabular}

The data collection started in July 2005, when the authors employed secondary data (e.g. online journals or newspapers), analysed the Bookcrossing website and informally interviewed a few Bookcrossing members to better understand how the community works. In October 2005, the 
authors started the netnographic analysis, which is still continuing. Online sources were specifically selected in keeping with Kozinets's (2002b) suggestions, according to which, they broadly illustrate the entire community without focussing on particular targets (see Table 1). The amount of data also drove the selection, as those sources that generated more data were given more scope. In total, the volume of downloaded text amounted to 1,604 double-spaced, 12-point font pages.

In addition, one of the authors became more involved in the community by creating an own webpage in March 2006. He read, registered and released his books, and attended the monthly meetings of local bookcrossers. Specifically, he attended 45 meet-ups (including a few national ones) in Italy, during which he collected data by taking field-notes and photographs. On the whole, the researcher played the role of a participant observer (Daymon and Holloway, 2002; Sayre, 2001); that is, his true identity and his role as researcher were revealed when he asked for permission to participate in the meetings.

Participant observation was also useful to find informants who would agree to be interviewed. Specifically, eight people of different gender, age, occupation and involvement in the community (see Table 2) were selected and interviewed. Six of them were interviewed during a meet-up, and two at a local bar. The interviews ranged from 30 minutes to an hour and were recorded and transcribed verbatim, resulting in 91 double-spaced pages of text. They generally began with a wideranging examination of the informants' backgrounds and their motivations for participating in the Bookcrossing community, after which they focused more on the specific community rituals in which they participated (e.g. the degree to which they participated in online discussions, how often they attended local meetings, how they 'released' their books, etc.).

\begin{tabular}{|c|c|c|c|c|}
\hline \multicolumn{5}{|c|}{ Table 2 - Informants' demographics and involvement } \\
\hline Subject & Gender & Age & Occupation & $\begin{array}{c}\text { Involvement }^{*}(\mathrm{H}=\text { High, } \mathrm{M}=\text { Medium, } \mathrm{L}= \\
\text { Low })\end{array}$ \\
\hline 1 & $\mathrm{~F}$ & 52 & Professor & $\mathrm{H}$ \\
\hline 2 & $\mathrm{~F}$ & 23 & Student, Photographer & $\mathrm{H}$ \\
\hline 3 & $\mathrm{~F}$ & 25 & Student & $\mathrm{H}$ \\
\hline 4 & $\mathrm{M}$ & 34 & Pharmacist & $\mathrm{H}$ \\
\hline 5 & $\mathrm{M}$ & 33 & Writer & $\mathrm{H}$ \\
\hline 6 & $\mathrm{~F}$ & 47 & Professor & $\mathrm{M}$ \\
\hline 7 & $\mathrm{M}$ & 36 & Attorney & $\mathrm{M}$ \\
\hline 8 & $\mathrm{~F}$ & 29 & Clerk & $\mathrm{L}$ \\
\hline
\end{tabular}

The application of these diverse methods made it possible to cross-check the evidence across different contexts and to increase the understanding of the community's specific traits and mechanisms. Following the suggestion by Romano et al. (2003), the data mass reduction was performed in three different phases (selection, coding and clustering), followed by the final interpretation. More specifically, selection involved considering the definition of 19 categories of topics (e.g. some of these categories were called 'sharing', 'community', 'rituals', 'gift-giving', 
'conflicts', etc.). This process was derived from previous theory, authors' research objectives and the data. Then, the codes to be used in the analysis were developed through a coding process. That is, based on theoretical relevance and word frequencies, specific groups of codes were defined and associated with the previously developed categories (e.g. codes such as 'consciousness of kind', 'moral responsibility' or 'I like to meet new friends' were related to the 'community' category). The authors identified separate lists of codes corresponding to the initial categories and then combined them in a final list of 143 codes. This process served as input for the clustering step, in which this list was used to code the data: that is, to associate observations (i.e. quotations) with the developed list of codes.

As recommended by Thompson (1997, p. 441), interpretation followed an iterative approach. That is, firstly, the texts were read to gain an initial sense of the whole; then, further readings helped to develop a more holistic and integrated understanding of the meaning of the texts. New insights were obtained by reconsidering previously analysed texts according to the newly emerging interpretation. Finally, the authors identified recurring patterns and differences across the various texts, which they used to better interpret the data. Spiggle's (1994, p. 497) reminder that 'interpretation results from an emergent, holistic, extralogical insight or understanding' was again very apt.

In order to better interpret the emerging codes, Atlas.ti v. 5.2 was specifically used to develop a semantic network for each of the 19 categories of interest and to analyse the emerging relationships (e.g. causality, association, contradiction, etc.) between the associated codes (see Figure 2). In this regard, the next section includes a few examples of quotations that were particularly significant in the data analysis and interpretation process.

\section{Findings}

As argued above, in order to fully comprehend how Bookcrossing and other consumer gift systems work, all of their facets have to be described to provide a complete description of their various consumption rituals and the goals that the members wish to achieve (Muñiz and O'Guinn, 2001; Ruth, 2004), which depend on the role they want to play in the community (Kates and Belk, 2001; Kozinets, 1999). Hence, the most important releasing rituals are presented in the following sub-section, followed by a brief description of the various typologies of bookcrossers. The most relevant characteristics of Bookcrossing rituals and profiles are also illustrated in Figure 2, which for purposes of exposition - is introduced at the beginning of the analysis rather than at the end, thus serving as a reference point for the reader. 


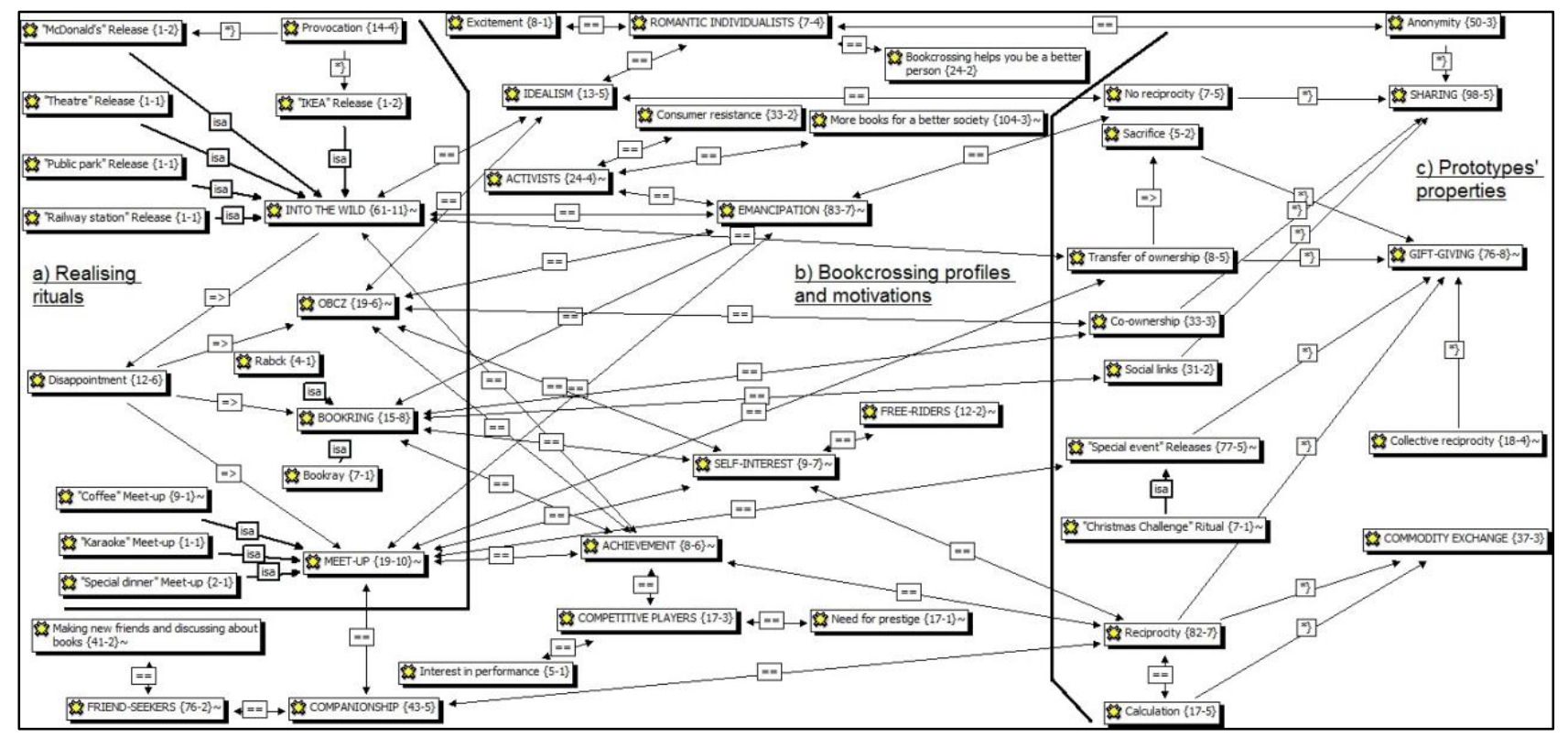

Figure 2. The main Bookcrossing rituals, profiles and prototypes

This recapitulatory network was created with Atlas.ti v. 5.2. The various nodes represent a few of the codes that emerged from the empirical data. Groundedness and density are specifically indicated when curly brackets follow the code name. Groundedness is indicated by the first number in the curly brackets, which is the number of quotations associated with one code. Large numbers indicate strong evidence found for that code. The density is indicated after a dash: this is the number of codes linked to one code. Large numbers can be interpreted as a high degree of theoretical density. The tilde character " $\sim$ " flags commented codes, while capital letters identify particularly important nodes (i.e. codes) in this network. In addition, the relationships should be read as link prototypes used to create a link between two codes. In detail, the label "==" means that C1 isassociated-with $\mathrm{C} 2$; "=>" means that $\mathrm{C} 1$ is-cause-of $\mathrm{C} 2$; "isa" means that $\mathrm{C} 1$ is-a $\mathrm{C} 2$; and "* $\}$ " means that $\mathrm{C} 1$ is-property-of $\mathrm{C} 2$. Finally, the network is divided into three parts to make it more understandable. The first section ('Realising rituals') includes nodes that represent the main Bookcrossing releasing rituals: the traditional 'into the wild' release and the more innovative 'OBCZ', 'Bookring' and 'Meet-up' releases. The second section ('Bookcrossing profiles and motivations') comprises nodes that illustrate the different Bookcrossing profiles (e.g. activists, friend-seekers, etc.) and their specific motivations for participating in these rituals (e.g. emancipation, companionship, etc.). The third section ('Prototypes' properties') contains nodes that identify gift-giving, sharing and commodity exchange, and disclose some of their key properties (e.g. reciprocity, co-ownership, etc.). 


\section{Releasing rituals}

Those purists who trust and promote the quintessential dimension of Bookcrossing believe that books' liberation means releasing them into the wild (see the code 'into the wild' in Figure 2): in a bar, railway station, public park, a theatre, or even in a McDonald's. This makes it possible to send a book out to look for someone who would not otherwise read it. In this sense, a book is usually represented (in the community jargon) as a 'message in a bottle' (code 'idealism'), which, as expressed by M. in the following extract, is probably the most exciting aspect of Bookcrossing:

\section{In 20 years my son could find one of my books in the street and could check the Bookcrossing website to ascertain my feelings and emotions about the book at the moment I released it. It's so exciting - like leaving a message in a bottle (M, Interview published in a local newspaper).}

Moreover, releasing books into the wild can also be seen as a social transformation project (code 'emancipation'): not only is this type of book-giving an example of expressive, emotional and altruistic gift-giving (Belk and Coon, 1993), but it could also be interpreted as an attempt to educate consumers and emancipate them from the market (Kozinets and Handelman, 2004; Murray and Ozanne, 1991).

This method of consuming books has certain similarities with the sharing and the gift-giving prototypes identified by Belk (2010). As with sharing, releasing books into the wild is nonreciprocal, which means that bookcrossers who do this, do not necessarily expect to receive a book in return (code 'no reciprocity'). Gift-giving should also be nonreciprocal, but, as Belk (2010, p. 718) rightly points out, in practice, it is reciprocal because it tends to be a utilitarian activity that allows groups to obtain mutual benefits. Consequently, many of the Bookcrossing community members clearly state that they are not interested in receiving anything in return because it should be a totally unselfish system. In addition, they usually describe this form of consumption as 'sharing':

\section{$\mathrm{Hi}, \mathrm{I}$ just joined in this great community. I simply love the idea of sharing books this way and will hopefully release my first book in just a couple of days. Keep sharing! ( $F$, Release Challenges)}

This seems to be a special form of anonymous sharing (code 'anonymity'). Unlike in Belk's (2010) definition, according to which sharing is a personal way of consuming goods or services, bookcrossers even seem to share with unknown people.

On the other hand, this ritual also shares certain characteristics with the gift-giving prototype. Contrary to typical sharing, it prompts a transfer of ownership (i.e. the donor has to permanently part with the book; code 'transfer of ownership') and, consequently, implies a sacrifice by the givers (code 'sacrifice'):

Which books do I give away? It is hard to part with them. I keep thinking my husband said he might read this one or that that was really good, and I don't want to part with it. (J, Activists Only) 
Therefore, many bookcrossers admit to buying extra copies of their favourite books in order to release one and to keep the other. Some of the members are particularly disappointed when they discover that nobody has found their released books, which happens frequently (code 'disappointment'). Accordingly, the difficulties encountered with successfully releasing books using just this ritual led individuals to invent other ways of exchanging them.

Books can, for example, now be swapped during what bookcrossers label 'meet-ups' (code 'meet-up'): that is, when members of local Bookcrossing groups meet to personally exchange books and to perform social rituals that go far beyond the essence of Bookcrossing: parties, pizza, karaoke, etc. (McAlexander et al., 2002). Thus, the meet-ups are the social side of Bookcrossing: although they are oriented toward typical Bookcrossing exchanges, they also serve as a relational setting in which the participants' main goal seems to be to make new friends (code 'companionship'). Consequently, tension may arise when more committed members take part in a meet-up and feel that the others are not sufficiently committed to the more authentic aspects of Bookcrossing.

Meet-ups have become particularly popular because bookcrossers are sure that someone will accept the books they bring with them and register them. Since they are very efficient as a form of safe release, especially members interested in performance, competition and prestige actively participate in such exchanges (code 'achievement').

Notably, this form of exchange cannot be considered a pure form of gift-giving; instead, it could also be associated with that which Belk (2010, p. 718) defines as commodity exchange. As in the case of gift-giving, a meet-up generates the transfer of ownership and is performed during particular occasions, such as ceremonies, parties or special events (code “'special event" releases'). However, it is highly reciprocal (code 'reciprocity'); thus, it can also be considered a commodity exchange. Furthermore, people participating in these meetings not only aim to receive certain books in return, but would also like to develop new social relationships with other book lovers. As noted in the next comment, this aspect sometimes becomes even more important than the main idea of releasing books to change the world:

\begin{abstract}
As in many other communities, the human aspect is becoming increasingly central. Interpersonal relationships and links are becoming more important than releasing any other book... I feel we risk losing sight of the original objective for which we met one another and became friends... and I wonder: where is Bookcrossing going? Is there a future? Is it only an excuse to drink or eat together and only share books among ourselves? (Direct Interview, Subject n 1)
\end{abstract}

Again, the gifts are not intended in their pure form; instead, they are especially used as symbolic instruments to develop and cement friendly relationships (Weiner, 1992).

Additionally, books can also be released in libraries, bars and shops with a dedicated room for bookcrossers defined as 'OBCZs' (Official Bookcrossing Zones; code 'OBCZ'). They are very effective for individuals interested in release performance: as in the case of meet-ups, it is very likely that a book will be taken and be registered again. Moreover, there is room for free-riders who, unlike at meet-ups in which there is more social control over the exchange process, might even receive 
books without releasing any (code 'self-interest'). On the other hand, OBCZs are also very promising for those interested in higher values and objectives: OBCZs are dedicated spots in which the Bookcrossing philosophy can be witnessed and adequately represented.

Consequently, it is difficult to associate this form of release with one of the various paradigms (commodity exchange, gift-giving and sharing) that Belk (2010) defined. Like sharing, it implies a type of co-ownership: members of a particular area may regard these zones as types of "public libraries' where they can leave their shared books (code 'co-ownership'). However, as with release into the wild described above, this can also be considered a form of anonymous sharing, since the releasers and recipients who use the same OBCZ do not generally know each other, nor do they meet to exchange books. Thus, contrary to what Belk (2010) suggests, they seem to share the same books without having a personal relationship.

Furthermore, since the majority of people who leave their books take others and vice versa, this form of release only seems nonreciprocal, but is reciprocal in practice. Consequently, it also shares a few traits with the gift-giving construct. Nevertheless, compared to the traditional dyadic form of gift-giving (e.g. Sherry, 1983), it seems to be based on a different reciprocity norm. That is, the recipient is not obliged to re-gift the releaser, although he or she should feel grateful toward the entire community and should reciprocate it by, for example, releasing other books in the OBCZ (code 'collective reciprocity').

Finally, because competitive players can also use this particular form of release as an instrument to increase their score, it may even be associated with commodity exchange. That is, the givers are almost guaranteed that this release will be received by someone else - very likely another Bookcrossing member, who will register it on the website:

\footnotetext{
Actually, an OBCZ release is a sort of 'indoor into the wild release'... it's fascinating as an 'into the wild release', but you're also sure that your book won't be lost. I sometimes prefer this way exactly for this reason... Too often I didn't hear anything about my books again! (Direct Interview, Subject n 3)
}

Therefore, more dimensions seem to coexist. Specifically, the same ritual tends to be interpreted in different ways by the members who use it to satisfy different and often idiosyncratic objectives: improving performance, obtaining good books in exchange for bad ones, promoting the community, and so on. This also occurs in the most recent release mode: the one which bookcrossers label 'bookrings' (code 'bookring'). Bookrings are lists of people registered on the website as wishing to receive a specific book. That is, the participants in a bookring wait for their turn to receive a specific book and, once they have read and registered it, they send it to the next member, usually by surface mail. The last bookcrosser on the list returns the book to the first one and the ring starts again. There are also various modes in which bookrings can be established: for instance, in the 'bookray' mode, the last participant is expected to release the book into the wild, while, in the 'RABCK (Random Acts of Bookcrossing Kindness)' mode, the giver does not expect to receive anything in return, not even reimbursement of his or her postage charges. 
If we accept Belk's (2007, p. 126) definition of sharing as 'the act and process of distributing what is ours to others for their use and/or the act and process of receiving or taking something from others for our use', bookrings can certainly be understood as actual examples of sharing. This form of consuming books creates social links to others and originates in a network of people who share the experience of reading and possessing the same book almost simultaneously (code 'social links'). However, it also shares certain characteristics with gift-giving, since it tends to be reciprocal in practice. To this end, it is worth highlighting that, as in the case of OBCZ releases, this is not a dyadic gift-giving; instead, a collective form of reciprocity seems to structure this ritual. That is, the recipient has no obligation to the donor. Conversely, he or she should feel grateful toward the community and should reciprocate by releasing the book to the next member.

Additionally, since all the various types of bookrings have effectiveness (e.g. people searching for a specific book can easily enter a ring and obtain it) and efficiency (e.g. books are sent, received and returned, and each exchange implies an entry in the release journal) in common, they mostly provide scope for people who only participate in the ritual to read a book in which they are interested and those who aim at increasing their number of read and released books (code 'calculation'). In other words, bookrings even seem to have things in common with commodity exchange (Larsen and Watson, 2001), during which people only give something to receive something else in return.

Bookrings and related rituals are developing rapidly, which seems to offend the committed members: although releasing books into the wild is expensive and precarious, this is the essence of Bookcrossing. Thus, many members complain about the diffusion of new methods that they consider inappropriate to adequately promote the community and attract new people. As previously noted (e.g. Kates and Belk, 2001), this important trend implies that consumption communities are not homogeneous; instead, people regard them from many different perspectives. Bookcrossing appeals to individuals who believe that ideological and romantic objectives are more important and to those who just want to accumulate as many registered releases as they can. Other members are simply looking for a book and do not care about Bookcrossing's communal dimension. Consequently, conflicts and debates often arise in the forums when these perspectives interact with one another. Although all these profiles relate to the same basic essence, they seem to have very different expectations, motivations and objectives (see also Fournier and Lee, 2009; Martin et al., 2006).

The next section provides a brief description of the most common roles performed within the community (see also Dalli and Corciolani, 2008). 


\title{
Bookcrossing profiles
}

The most important profile is that of an activists (code 'activists'), which - as the following quotation shows - refers to those members interested in developing Bookcrossing in its purest form and who are, simultaneously, concerned with the emancipatory nature of the system (Kozinets and Handelman, 2004):

\begin{abstract}
You made my day when I discovered this website! What an incredible idea! What better way to foster goodwill and a do a good deed than (sic) to pass on a book, free to anyone. You could change someone's life by such an unselfish act. I must say I smiled all day after releasing my first book 'into the wild' at a local McDonalds. (S, Testimonials)
\end{abstract}

Similarly, romantic individualists (code 'romantic individualists') also believe in the most authentic form of Bookcrossing. Unlike activists, however, they do not want to have any formal commitment or recognition in the community. That is, they take the Bookcrossing philosophy seriously but only in their private life. Accordingly, they do not appear at social meetings, compete with other members, or even be recognized by other bookcrossers. In fact, they do not release books to receive something in return but merely to make a personal contribution towards society's improvement:
Jokes aside, I still go on in releasing books because I love it and sometimes you do receive some satisfaction in return. I do not exchange books at meet-ups, because I don't care about the so-called 'feedback'. I want to free books because I love the romantic spirit of this. And I think that perhaps those who receive the book don't want to register it, or perhaps can't. But the most important thing is that they read the book and perhaps feel joy, interest or simply companionship for that day. (A, Italian mailing list)

Although activists and romantic individualists fully embrace the Bookcrossing philosophy, it is worth emphasising that the community also comprises far less committed members. Friend-seekers (code 'friend-seekers'), for instance, mostly aim to get to know people and, they hope, develop new social relationships. Thus, while they are also interested in Bookcrossing, their relational motivation seems to be far more important than their interest in fulfilling the main Bookcrossing aims and scopes (Granitz and Ward, 1996):

\footnotetext{
If I have to guess the weight of different modes of participation, I would say $80 \%$ friendship and $20 \%$ other stuff, even very serious tasks, such as proselytising. (Direct Interview, Subject $\mathrm{n}$ 2)
}

Furthermore, there are free-riders (code 'free-riders') who exploit genuine or naive bookcrossers by, for example, asking for books and not returning them. However, more expert members actively control these behaviours. On the other hand, as Lois remarks (1999), this type of communities is necessarily subjected to free-riding. This happens when certain members participate in a utilitarian fashion, taking advantage of the lack of rules and sanctions, as well as of the adequate incentive systems that support altruistic behaviour. Hence, it is difficult to safeguard the community against free-riding. However, although free-riders try to exploit newbies and more generous members, their behaviour also has positive effects on the community. For example, they increase the number of 
books that are actually registered and released; they develop a positive word-of-mouth, etc. (see also Giesler, 2006).

Finally, competitive players (code 'competitive players') love to follow the history of their books on the website. They consider them characters (like the heroes or protagonists in an adventure) they have created and sent out into the world:

\footnotetext{
With Bookcrossing I will be able to find out where my books have travelled. I just released several books in my local area and I am anxiously waiting to see where they go. (W, Testimonials)
}

As in other, similar, contexts (Kozinets, 2002a; O'Guinn and Muñiz, 2005), they also play an important role within the community. Since they are especially interested in increasing their number of registered, released and found books in order to compete with other members, they support the circulation of books and the diffusion of the Bookcrossing name significantly.

In sum, the evidence provided above shows that the Bookcrossing community works as a complex system of collective ritualised behaviours suited to the diversified, individual objectives of different member profiles. Furthermore, these rituals possess different dimensions that can be associated with commodity exchange, gift-giving and sharing, as will be discussed in the next section.

\section{Theoretical implications}

This paper seeks to contribute to the recent debate on gift-giving, sharing and commodity exchange (Bardhi and Eckhardt, forthcoming; Belk, 2010; Giesler, 2006; Marcoux, 2009; Weinberger and Wallendorf, 2012). As summarised in Figure 3, Bookcrossing works as a combination of various rituals related to different aspects of commodity exchange, gift-giving and sharing that thus coexist and are integrated. An into the wild release may, for instance, be considered an example of sharing (i.e. it is nonreciprocal), but, as mentioned above, it also has a few important similarities with giftgiving as it implies a transfer of ownership; consequently, it entails a sacrifice (Belk and Coon, 1993; Sherry, 1983). Meet-ups are more like gift-giving, since they are contexts in which bookcrossers simply meet to exchange books. However, since the pure gift should be nonreciprocal (Belk and Coon, 1993), these exchanges might also be seen as commodity exchanges (see also Sherry et al., 1993) in the form of barter. In the OBCZ releases, another example of sharing emerges as the members create a type of public library whose books they share (Belk, 2007). There are, however, also signs of other prototypes, since this form of exchange is actually reciprocal, like gift-giving, and sometimes entails a balanced exchange, as with commodity exchange (Belk, 2010). Similarly, bookrings also seem to be an example of sharing (e.g. they imply social links to others and networked inclusion), but, similar to gift-giving exchanges, they include some sort of reciprocity and, as commodity exchanges, they may entail some calculation (see Belk and Coon, 1993).

Hence, the analysis of Bookcrossing helps us understand that a consumption community may not only be associated with one type of exchange. On the contrary, the analysis expands previous 
theories by arguing that it is necessary to take different approaches into account in order to appropriately describe the multi-faceted consumption activities that communities' members perform. Specifically, as also noted in Figure 3, it seems that this differentiation is rooted in the members' different profiles (and related purposes): they approach Bookcrossing in different ways and participate with different levels of commitment and self-identification (Dalli and Corciolani, 2008; MacLaran and Masterson, 2006). Consequently, although previous analyses of consumer gift systems have focused mostly on members' altruistic attitudes and behaviours (Giesler, 2006), this work explains that people who belong to these communities play different roles and use gift-giving and other forms of exchange that are consistent with their personal objectives, identities and motivations (e.g. Fournier and Lee, 2009). Romantic individualists and activists, for example, mostly undertake an into the wild release; competitive players (Giesler, 2006; Kozinets, 2002a) may also be attracted by this ritual, while those with other profiles seem to prefer other ways of releasing their books. Friend-seekers and free-riders, together with activists and competitive players, are particularly willing to use more effective and efficient instruments, such as meet-ups (Granitz and Ward, 1996). OBCZ releases also involve participants with different profiles - activists, competitive players, free-riders and romantic individualists - who have differing motivations (i.e. emancipation, achievement, self-interest and idealism), and mainly prefer this way of releasing books. The same applies to bookrings, which specifically attract competitive players and free-riders (Lois, 1999), but also activists.

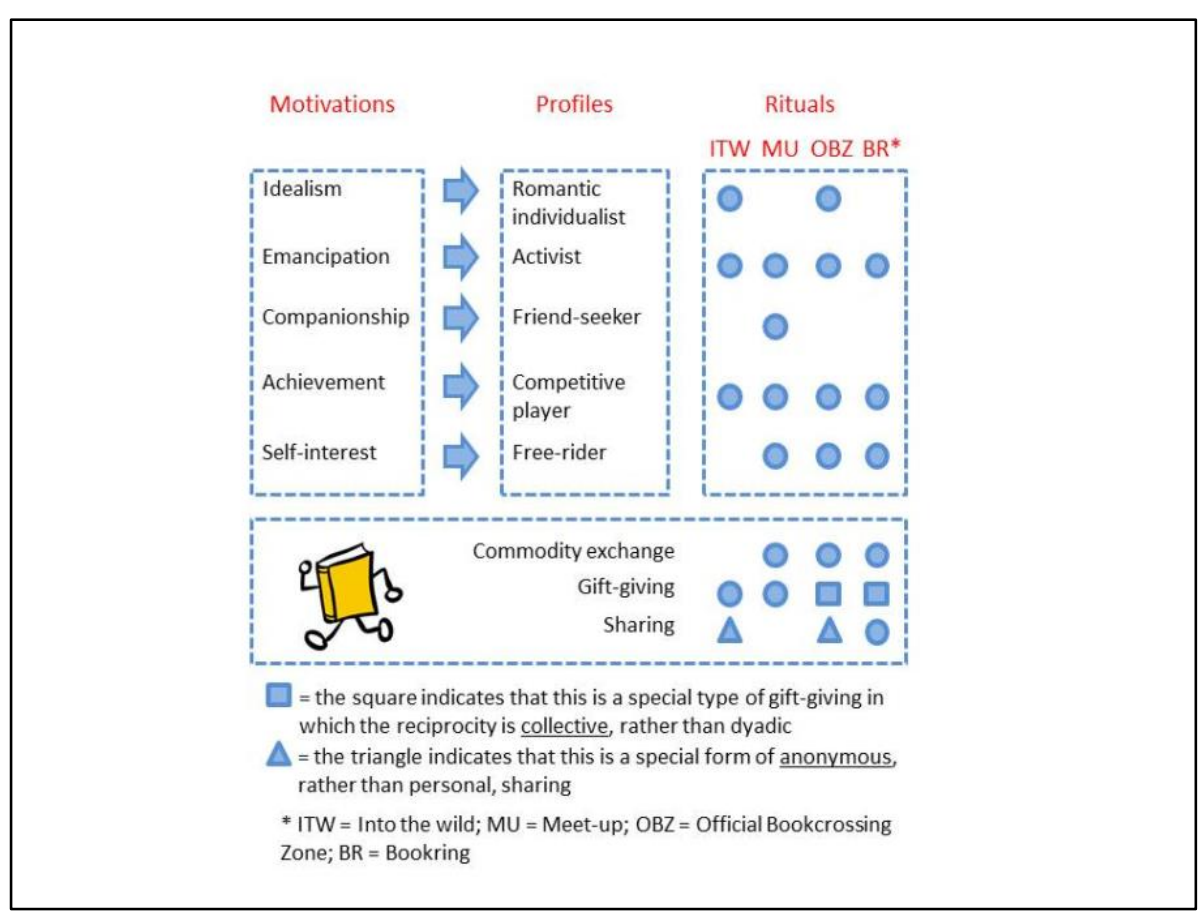

Figure 3. Motivations, profiles, rituals and prototypes within Bookcrossing

Beyond highlighting that different rituals are performed within the same consumer gift system, this analysis helps shed light on new characteristics of sharing and gift-giving that previous studies 
have not fully taken into consideration (e.g. Belk, 2010). Firstly, it shows that sharing does not necessarily have to be a 'personal' activity (Belk, 2010, p. 721). As specifically noted in Figure 2, into the wild and OBCZ releases have many characteristics in common with the sharing construct defined by Belk (2010). However, unlike the pure form of sharing described by Belk (2010), they are anonymous forms of sharing. In practice, many bookcrossers want to feel like members of a group and share their resources with others, without necessarily knowing them. Similarly, Weinberger and Wallendorf (2012) describe a special Mardi Gras festival in which individuals exchange particular forms of anonymous gifts. In this ritual, the gift-givers are generally masked, they all wear costumes and are all on floats; the recipients cannot identify them when they receive their gifts. Bookcrossing thus extends this possibility to sharing. In particular, members who go to OBCZs to release their books use these public libraries to share their books with people they do not know. Similarly, people releasing books into the wild aim at ideally transforming the entire world into a type of huge (public) library in which they share books with other (unknown) individuals. Thus, although previous research specifically noted this trend with reference to digital objects (e.g. Giesler, 2006), consumers seem willing to even (anonymously) share their physical products.

Secondly, this research challenges Belk's (2010) view of reciprocity, according to which only sharing is purely nonreciprocal, while gift-giving often tends to be a reciprocal exchange in practice (Belk and Coon, 1993; Marcoux, 2009; Sherry, 1983). In the case of Bookcrossing, a different form of 'collective' reciprocity seems to play an important role. When bookcrossers release a book in an OBCZ, for example, they do not expect anything in return from the individual who receives their book; at most, they may feel justified to take another book from the public library. Similarly, in the case of a bookring release, they do not expect anything in return from the person to whom they send a book, because he or she will actually read the book and pass it on to another community member. Giesler (2006) previously examined the new norms of (communal) reciprocity but, as he clearly notes ( $p$. 287), 'Napster's gift of music is a nonsacrifical gift in that it remains with the donor after the transaction'. Therefore, his reflections cannot be directly applied to the context of Bookcrossing in which, as noted, people have to part with their physical objects, which implies a major sacrifice. From this point of view, gift-giving among bookcrossers rather resembles the 'intracommunity gifting' introduced by Weinberger and Wallendorf (2012). However, in the context described by these two authors, there are generally two groups (members of a higher social position and those of a lower social position) and gift-giving moves from the first towards the second group. Within the Bookcrossing community, this particular form of reciprocity is shared by all the members and does not entail any role or status differences. Furthermore, intracommunity gifting generally occurs in a local community and is a wholly offline experience, while Bookcrossing is a world-wide community that uses the Internet to create a global community of readers.

\section{Managerial implications}


Bookcrossing is an interesting example of a consumer gift system in which the exchanged object is a physical and not a digital product. Many studies of peer-to-peer communities have mostly dealt with digital objects, such as mp3s (Giesler, 2006). Belk (2010, p. 729) also highlights that online communities are more willing to share than offline arenas. However, Bookcrossing shows that consumers are currently also creating alternative ways of consuming physical objects, such as books. In practice, individuals could now develop new systems for exchanging products that, based on gift-giving and sharing relationships, may even work without directly interacting with the traditional marketplace (Anderson, 2006, 2009; Bardhi and Eckhardt, forthcoming). Furthermore, this is not only true for digital files, which can be easily copied, but also for material objects. Notably, while sharing digital files is not a real sacrifice for consumers, who can keep their original copy on their PC (Giesler, 2006), giving books as a gift means parting with them, which implies an actual sacrifice for many readers. Therefore, as Bardhi et al. (forthcoming) also note, individuals seem to be moving toward a more detached and flexible relationship with possessions, which they term 'liquid'.

In the case of Bookcrossing.com, the books were originally sold, thus bookcrossers still need the market to purchase them. However, bookcrossers believe that, if their idealistic aims were to be developed further, they could simply buy new books, avoid buying old ones, and use the Bookcrossing system to share them. From a managerial point of view, it is important to note that, although books are sold regularly, their life expectancy tends to be longer. That is, they are not read and owned by a single customer but are shared by several consumers. Moreover, Bookcrossing.com is not the only system currently used to share books; other communities (see Bookmooch.com for another interesting example) have been created to allow people to swap books. Thus, new developments in consumer culture and internet-based technologies are driving consumers to new ways of interacting with consumption goods; the trends are thus moving from digital industries (software, music, etc.) to physical goods industries. These trends are leading to new business models that could shape the competitive scenario significantly; Bookcrossing.com and other examples from a number of industries are examples of this kind of development.

Owing to the impact of Bookcrossing.com, companies in the publishing industry may operate in two complementary ways: firstly, companies could develop new business models aimed at satisfying consumers' need to exchange and share consumption goods. An interesting example is that of Paperbackswap.com, a book club whose members only need to pay a few dollars to help support the club. Subsequently, they are allowed to post all the books they would like to swap on their page, and 'order' books in which they are interested from other members. When sending their books to others, they have to pay postage, but this is refunded when they receive the books. When a book is received, the giver gains one credit that can be used to order another book from another member. Secondly, publishing companies could also use more traditional tools to interact and collaborate with these new systems. They could, for example, sponsor particular online forums in which they could launch specific discussion threads. Additionally, they could create new packaging formats for their 
books and include appropriate features to satisfy bookcrossers, such as a pocket that might contain Bookcrossing labels. More significantly, they could also become partners of websites, such as Bookcrossing.com, and support the community in exchange for a direct link on their page. Amazon.com, for instance, uses this strategy with Bookcrossing.com.

In this regard, this study provides interesting insights since it helps explain the fundamental mechanisms that enable consumer gift systems to work. A company interested in dealing with this particular target should specifically take its rituals, profiles and motivations into consideration. This is the only way of avoiding problems that might emerge, especially with purists (i.e. activists and romantic individualists) who mainly participate in these communities for ideological and transformative objectives. They might therefore not easily accept the idea of the community engaging in more commercial activities or simply transforming itself. For example, if the community management decided to adapt Bookcrossing.com to a technological realm, they might interpret this idea as an inauthentic attempt to embrace a commercial trend. Although competitive players or freeriders may merely aim at having fun or achieving personal results, the most involved members may share more idealistic objectives and, consequently, pay more attention to these issues. Therefore, in order to deal with these particular communities, it is necessary to thoroughly analyse their members' attitudes, motivations and behaviours, and to take their specific rituals into consideration. From the management theory and practice point of view, this knowledge seems to be necessary, as it will impact the management of such communities as well as their competitors. In many industries, collaborative consumption is already emerging as a major source of competition for traditional business models (see http://collaborativeconsumption.com).

To this end, new research should be undertaken that can produce new evidence of these important phenomena. Although the ideas discussed in this article might be applied to other communities and market offerings (e.g. CDs, DVDs and other second-hand products), this analysis is only based on one community and one product type. Therefore, further analyses are required that incorporate other examples in order to integrate and generalise this study's results.

\section{References}

Albinsson, P.A. and Yasanthi Perera, Y. (2012), "Alternative marketplaces in the 21st Century: Building community through sharing events", Journal of Consumer Behaviour, Vol. 11, No. 4, pp. 303-15.

Anderson, C. (2006), The Long Tail: Why the Future of Business is Selling Less of More, Hyperion, New York, NY.

Anderson, C. (2009), Free: The Future of a Radical Price, Hyperion, New York, NY.

Arnould, E.J. and Price, L.L. (2006), "Market oriented ethnography revisited", Journal of Advertising Research, Vol. 46, No. 9, pp. 251-63.

Arnould, E.J. and Thompson, C.J. (2005), "Consumer culture theory (CCT): Twenty years of research", Journal of Consumer Research, Vol. 31, No. 4, pp. 868-82.

Arnould, E.J. and Wallendorf, M. (1994), "Market-oriented ethnography: Interpretation building and marketing strategy formulation", Journal of Marketing Research, Vol. 31, No. 4, 484-504. 
Arsel, Z. and Dobscha, S. (2011), "Hybrid pro-social exchange systems: The case of Freecycle," in Advances in Consumer Research 2011 (Vol. 39) Proceedings of the American conference in Duluth, MN, 2011.

Bagozzi, R.P. (1975), "Marketing as exchange", Journal of Marketing, Vol. 39, No. 4, pp. 32-9.

Bardhi, F. and Eckhardt, G.M. (forthcoming), "Access-based consumption: The case of car sharing", Journal of Consumer Research.

Bardhi, F., Eckhardt, G.M. and Arnould, E.J. (forthcoming), "Liquid relationship to possessions", Journal of Consumer Research.

Becker, J.U. and Clement, M. (2006), "Dynamics of illegal participation in peer-to-peer networks: Why do people illegally share media files?", Journal of Media Economics, Vol. 19, No. 1, pp. 7-32.

Belk, R.W. (2007), "Why not share rather than own?", Annals of the American Academy of Political and Social Science, Vol. 611, No. 1, pp. 126-40.

Belk, R.W. (2010), "Sharing", Journal of Consumer Research, Vol. 36, No. 1, pp. 715-34.

Belk, R.W. and Coon, G.S. (1993), "Gift giving as agapic love: An alternative to the exchange paradigm-based on dating experiences", Journal of Consumer Research, Vol. 20, No. 3, pp. 393417.

Benkler, Y. (2006), The Wealth of Networks: How Social Production Transforms Markets and Freedom, Yale University Press, New Haven, CT and London.

Cheal, D. (1988), The Gift Economy, Routledge, London.

Cova, B. (1997), "Community and consumption: Towards a definition of the linking value of products or services", European Journal of Marketing, Vol. 31, No. 3/4, pp. 297-316.

Cova, B., Kozinets, R.V. and Shankar, A. (2007), "Tribes, Inc.: The new world of tribalism", in Cova, B., Kozinets, R.V. and Shankar, A. (Eds.), Consumer Tribes: Theory, Practice, and Prospects, Elsevier/Betterworth-Heinemann, London, pp. 3-26.

Cova, B. and White, T. (2010), "Counter-brand and alter-brand communities: The impact of Web 2.0 on tribal marketing approaches", Journal of Marketing Management, Vol. 26, No. 3, pp. 256- 70.

Dalli, D. and Corciolani, M. (2008), "Collective forms of resistance: The transformative power of moderate communities. Evidence from the Bookcrossing case", International Journal of Market Research, Vol. 50, No. 6, pp. 757-75.

Daymon, C. and Holloway, I. (2002), Qualitative Research Methods in Public Relations and Marketing Communications, Routledge, London.

Fournier, S. and Lee, L. (2009), "Getting brand communities right", Harvard Business Review, Vol. 87, No. 4, pp. 105-11.

Giesler, M. (2006), “Consumer gift systems”, Journal of Consumer Research, Vol. 33, No. 3, pp. 283-90.

Granitz, N.A. and Ward, J.C. (1996), "Virtual community: A sociocognitive analysis", in Advances in Consumer Research, 1996 (Vol. 23) Proceedings of the American conference in Provo, UT, 1996, pp. 161-66.

Hine, C. (2000), Virtual Ethnography, Sage, London.

Hollenbeck, C.R., Peters, C. and Zinkhan, G.M. (2006), "Gift giving: A community paradigm", Psychology and Marketing, Vol. 23, No. 7, pp. 573-95.

Kates, S.M. and Belk, R.W. (2001), "The meanings of lesbian and gay pride day: Resistance through consumption and resistance to consumption", Journal of Contemporary Ethnography, Vol. 30, No. 4, pp. 392-429.

Kozinets, R.V. (1999), "E-tribalized marketing? The strategic implications of virtual communities of consumption", European Management Journal, Vol. 17, No. 3, pp. 252-64.

Kozinets, R.V. (2002a), "Can consumers escape the market? Emancipatory illuminations from burning man", Journal of Consumer Research, Vol. 29, No. 1, pp. 20-38.

Kozinets, R.V. (2002b), "The field behind the screen: Using netnography for marketing research in online communities", Journal of Marketing Research, Vol. 39, No. 1, pp. 61-72.

Kozinets, R.V. (2010), Netnography. Doing Ethnographic Research Online, Sage, London.

Kozinets, R.V. and Handelman, J.M. (2004), "Adversaries of consumption: Consumer movements, activism, and ideology", Journal of Consumer Research, Vol. 31, No. 3, pp. 691-704.

Larsen, D. and Watson, J.J. (2001), "A guide map to the terrain of gift value, Psychology and Marketing, Vol. 18, No. 8, pp. 889-906. 
Lois, J. (1999), "Socialization to heroism: Individualism and collectivism in a voluntary search and rescue group", Social Psychology Quarterly, Vol. 62, No. 2, pp. 117-35.

MacLaran, P. and Masterson, R. (2006), "You can't tell a book by its cover: Bookworms, bookcases, and Bookcrossing", in Brown, S. (Ed.), Consuming Books. The Marketing and Consumption of Literature, Routledge, London, pp. p. 126-37.

Marcoux, J.S. (2009), "Escaping the gift economy”, Journal of Consumer Research, Vol. 36, No. 4, pp. 671-85.

Martin, D.M., Schouten, J.W. and McAlexander, J.H. (2006), "Claiming the throttle: Multiple feminities in a hyper-masculine subculture", Consumption, Markets and Culture, Vol. 9, No. 3, pp. 171-205.

McAlexander, J.H. Schouten, J.W. and Koenig, H.F. (2002), "Building brand community", Journal of Marketing, Vol. 66, No. 1, pp. 38-54.

McCracken, G.D. (1988), The Long Interview, Sage, Newbury Park, CA.

Muñiz, A.M. and O'Guinn, T.C. (2001), "Brand community", Journal of Consumer Research, Vol. 27, No. 4, pp. 412-32.

Murray, J.B. and Ozanne, J.L. (1991), "The critical imagination: Emancipatory interests in consumer research, Journal of Consumer Research, Vol. 18, No. 2, pp. 129-44.

O'Guinn, T.C. and Muñiz, A.M. (2005), "Communal consumption and the brand", in Rumbo, J.D. and Mick, D.G. (Eds.), Inside Consumption: Frontiers of Research on Consumer Motives, Goals, and Desires, Routledge, New York, NY, pp. 472-508.

Raymond, E.S. (1999), The Cathedral and the Bazaar: Musings on Linux and Open Source by an Accidental Revolutionary, O'Reilly, Cambridge, MA.

Romano, N.C., Donovan, C., Chen, H.C. and Nunamaker, J.F. (2003), "A methodology for analyzing web-based qualitative data", Journal of Management Information Systems, Vol. 19, No. 4, pp. 213-46.

Ruth, J.A. (2004), "Gift exchange rituals in the workplace. A social roles interpretation", in Otnes, C. and Lowrey, T.M. (Eds.), Contemporary Consumption Rituals: A Research Anthology, Lawrence Erlbaum, Mahwah, NJ, pp. 181-211.

Sayre, S. (2001), Qualitative Methods for Marketplace Research, Sage, Thousand Oaks, CA.

Scaraboto, D. (2010), "From the web to the woods. Connecting the online to the offline in consumers' play", in Advances in Consumer Research 2010 (Vol. 37) Proceedings of the American conference in Pittsburgh, PA, 2010.

Schouten, J.W. and McAlexander, J.H. (1995), "Subcultures of consumption: An ethnography of the new bikers, Journal of Consumer Research, Vol. 22, No. 1, pp. 43-61.

Sherry, J.F. (1983), "Gift giving in anthropological perspective", Journal of Consumer Research, Vol. 10, No. 2, pp. 157-68.

Sherry, J.F., McGrath, M.A. and Levy, S.J. (1993), "The dark side of the gift", Journal of Business Research, Vol. 28, No. 3, pp. 225-44.

Spiggle, S. (1994), "Analysis and interpretation of qualitative data in consumer", Journal of Consumer Research, Vol. 21, No. 3; pp. 491-503.

Thompson, C. (1997), "Interpreting consumers: A hermeneutical framework for deriving marketing insights from the texts of consumers' consumption stories", Journal of Marketing Research, Vol. 34, No. 4, pp. 438-55.

Weinberger, M.F. and Wallendorf, M. (2012), "Intracommunity gifting at the intersection of contemporary moral and market economies", Journal of Consumer Research, Vol. 39, No. 1, pp. 7492.

Weiner, A.B. (1992), Inalienable Possessions: The Paradox of Keeping-while-giving, University of California Press, Berkeley, CA.

Zeitlyn, D. (2003), "Gift economies in the development of open source software: Anthropological reflections”, Research Policy, Vol. 32, No. 7, 1287-91. 